\title{
Pine defense responses to eggs of an herbivorous sawfly are elicited by an annexin-like protein
}

\author{
Janik Hundacker ${ }^{1}$, Norbert Bittner ${ }^{2}$, Christoph Weise ${ }^{2}$, Gunnar Bröhan ${ }^{1}$, Martti Varama ${ }^{3}$, \\ and Monika Hilker ${ }^{1}$ \\ ${ }^{1}$ Freie Universität Berlin \\ ${ }^{2}$ Freie Universitat Berlin \\ ${ }^{3}$ Natural Resources Institute Finland
}

August 3, 2021

\begin{abstract}
Known elicitors of plant defenses against eggs of herbivorous insects are low-molecular-weight organic compounds associated with the eggs. However, previous studies provided evidence that also proteinaceous compounds present in secretion associated with eggs of the herbivorous sawfly Diprion pini can elicit defensive responses in Pinus sylvestris. Pine responses induced by the proteinaceous secretion are known to result in enhanced emission of $(E)-\beta$-farnesene, which attracts egg parasitoids killing the eggs. Here, we aimed to identify the defense-eliciting protein and elucidate its function. After isolating the defenseeliciting protein from D. pini egg secretion by ultrafiltration and gel electrophoresis, we identified it by MALDI-ToF mass spectrometry as an annexin-like protein, which we named "diprionin". Further GC-MS analyses showed that pine needles treated with heterologously expressed diprionin released enhanced quantities of (E)- $\beta$-farnesene. Our bioassays confirmed attractiveness of diprionin-treated pine to egg parasitoids. Expression of several pine candidate genes involved in terpene biosynthesis and regulation of ROS homeostasis was similarly affected by diprionin and natural sawfly egg deposition. However, the two treatments had different effects on expression of pathogenesis related genes (PR1, PR5). Diprionin is the first eggassociated proteinaceous elicitor of indirect plant defense against insect eggs described so far.
\end{abstract}

\section{Hosted file}

Hundacker-et-al-2021-Diprionin-main-text.docx available at https://authorea.com/users/428806/ articles/532604-pine-defense-responses-to-eggs-of-an-herbivorous-sawfly-are-elicited-byan-annexin-like-protein 

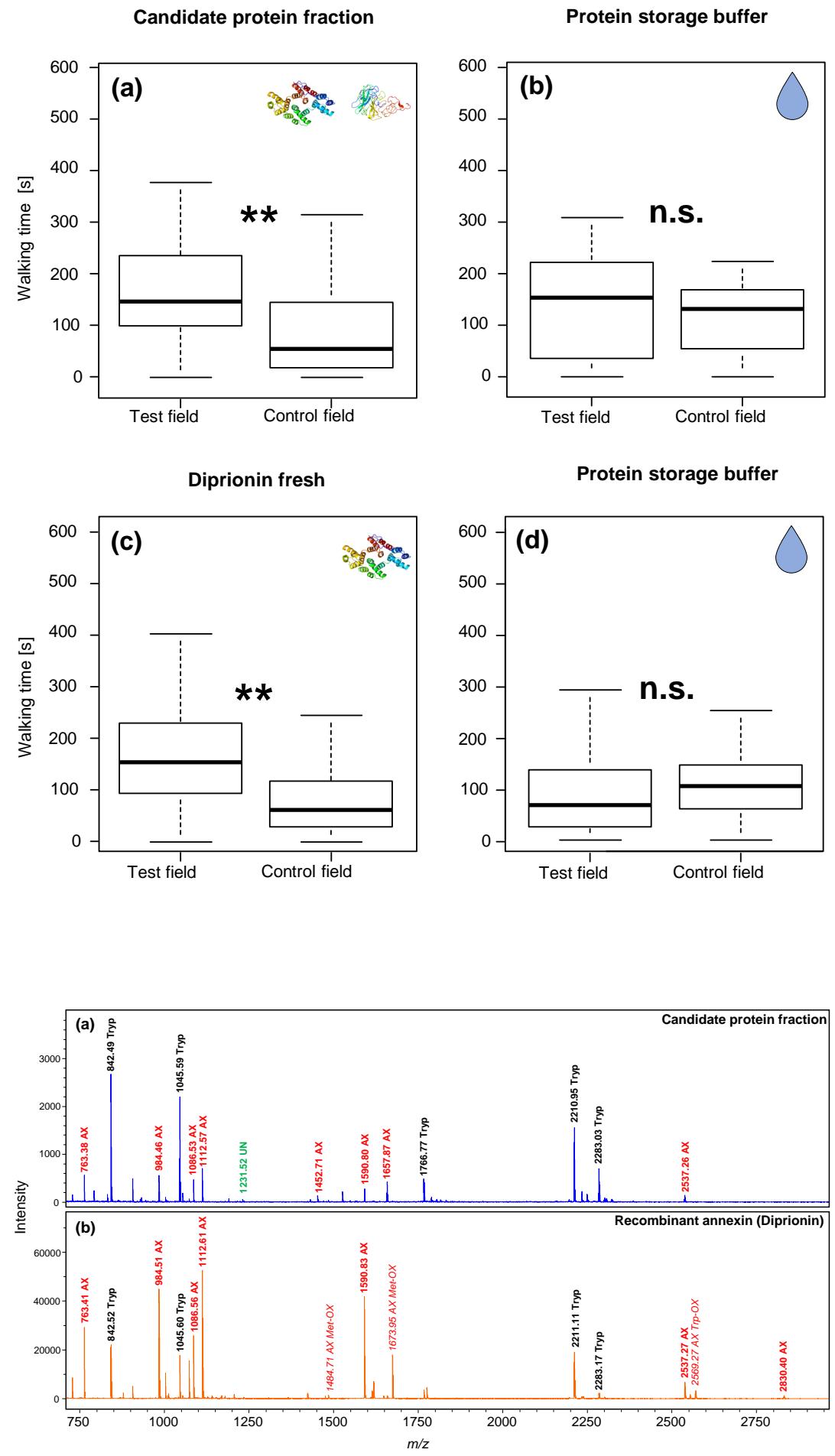
(a)
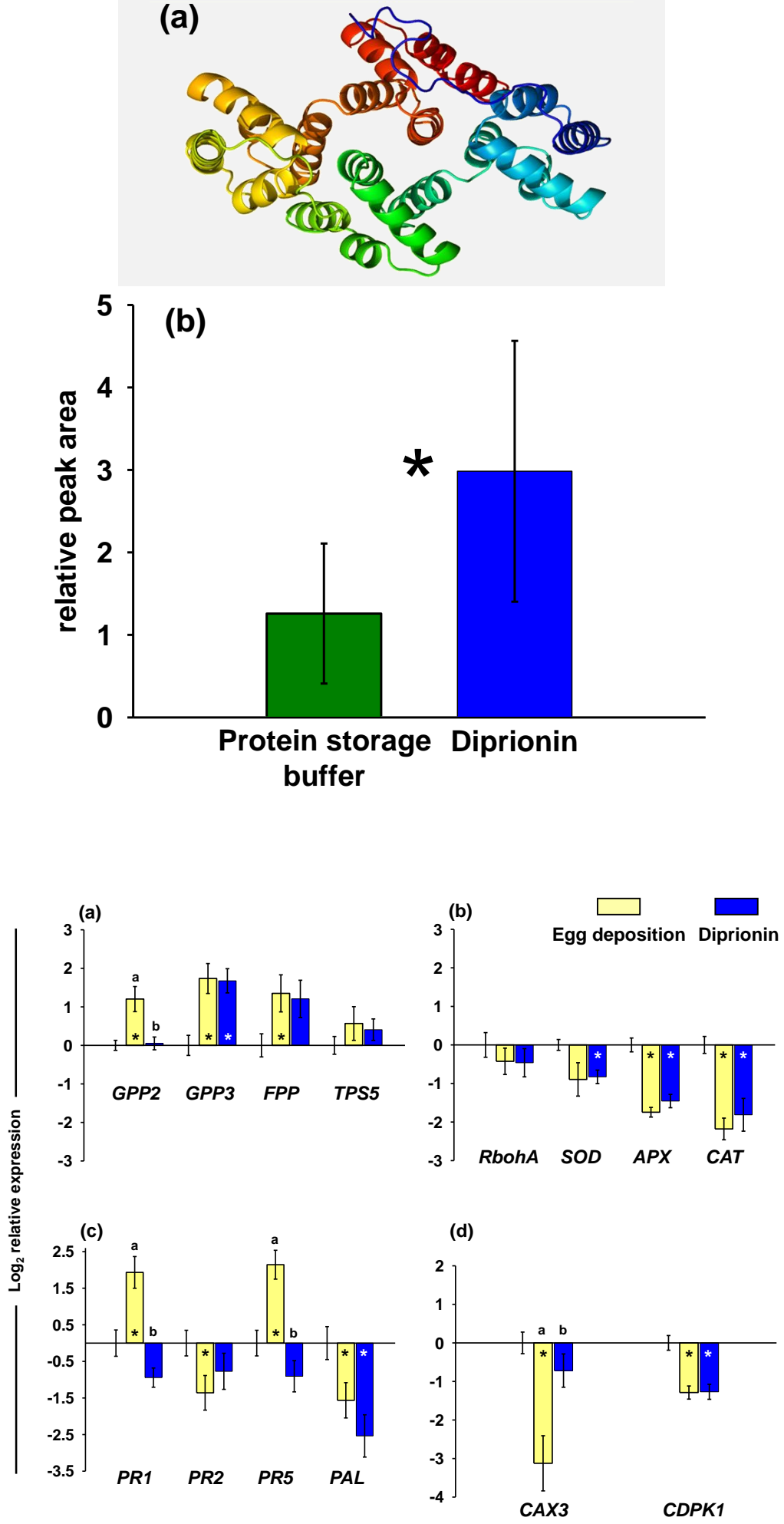